\title{
Effects of Dietary Herbal Supplementation on CASA Based Sperm Motion Traits in Subfertile Buffalo Bulls (Bubalus bubalis)
}

\author{
Shivkumar ${ }^{1 *}$, Ajeet Kumar', M. Honparkhe ${ }^{2}$, A.K. Singh ${ }^{2}$ and P.S. Brar ${ }^{2}$ \\ ${ }^{1}$ Department of Veterinary Clinical Complex, Veterinary College Gadag - 582101, \\ Karnataka, India \\ ${ }^{2}$ Department of Veterinary Gynaecology and Obstetrics, Guru Angad Dev Veterinary and \\ Animal Sciences University, Ludhiana - 141 004, Punjab, India \\ *Corresponding author
}

\section{A B S T R A C T}

The study was conducted to evaluate the combined effect of herbs on pre-freeze and postthaw sperm motion traits in subfertile buffalo bulls. Three subfertile buffalo bulls which were maintained on the basal ration along with this, they were orally supplemented with

\section{Keywords}

Subfertile buffalo bulls, Herbs, Prefreeze, Post-thaw, CASA, Sperm motion traits

Article Info

Accepted:

20 February 2018 Available Online: 10 March 2018 Panax ginseng roots, Shilajit, Withania somnifera roots, Tribulus terrestris fruits, Turnera diffusa leaves; Ptychopetalum olacoides bark each @ $400 \mathrm{mg} / 100 \mathrm{~kg}$ body weight and Pausinystalia yohimbe bark@300 mg/100 kg body weight of bulls for 60 days of treatment phase. A total of 144 semen ejaculates (16 ejaculates/ bull/ treatment phase) were collected during pre-treatment, treatment and post-treatment phase (each phase of 60 days). Semen was extended with Tris egg yolk extender and freezing was carried out in a bio-freezer. Semen was evaluated for sperm motion traits in pre-freeze and post-thaw semen by Computer Assisted Sperm Analyser (CASA). Herbal supplementation significantly $(\mathrm{P}<0.05)$ increased the pre-freeze curvilinear velocity $(\mathrm{VCL})$ during treatment phase and post-treatment phase, whereas VSL, STR and BCF were significantly $(\mathrm{P}<0.05)$ increased only during post-treatment phase. Moreover, herbal treatment significantly $(\mathrm{P}<0.05)$ improved the post-thaw individual motility during the treatment and posttreatment phase, whereas rapid progressive motility was significantly higher only during the treatment phase. It could be concluded that dietary supplementation of herbs in combination improved the sperm motion traits in subfertile buffalo bulls.

\section{Introduction}

Artificial insemination is expanding day by day to improve the production and genetic potential of indigenous cows. The success and efficiency of the artificial insemination primarily depends on semen quality of breeding bulls (Sharma et al., 2017). The quality of semen depends on many factors such as genetic, climatic, physiological and nutritional status (Parisi et al., 2014; Andrabi et al., 2009; Koonjaenak et al., 2007). Among these climatic factors, extreme temperature and humidity are producing excessive quantity of reactive oxygen species in the body cells and spermatozoa (Sharma et al., 2017). Therefore, the poor semen quality and freezability are major problems in breeding 
buffalo bulls (Khatun et al., 2013). Reactive oxygen species are the oxygen-based highly reactive molecules (superoxide anion, hydrogen peroxide, and hydroxyl ion) (Krumova et al., 2016), which have double pronged effects on sperm.

The normal physiological levels of ROS promote sperm motility, maturation, capacitation, acrosome reaction, fertilization and transmembrane signal transduction [Bansal and Bilaspuri, 2011; Rhee, 2006). On the other hand higher levels of ROS, causes lipid peroxidation (LPO) of polyunsaturated fatty acid present in sperm membrane (Shamsi et al., 2010; Vaisberg et al., 2005; Fujii et al., 2003). Lipid peroxidation decreases the fertility by increasing the sperm abnormality and DNA fragmentation. It also lowers the sperm concentration, motility, viability, epididymal maturation, sperm mitochondrial membrane potential and even outcome of assisted reproductive techniques (Fujii et al., Benedetti et al., 2012; Shamsi et al., 2010; Tunc et al., 2009; Kadirvel et al., 2009; Cheema et al., 2009; Oral et al., 2006; Greco et al., 2005; Chatterjee et al., 2001).

Therefore to alleviate subfertility problems, several therapeutic approaches such as allopathy, ayurveda and unani are being used. Moreover, evidences suggest that dietary supplementation of herbs improves semen quality in animals and human.

So, in this experiment the subfertile bulls were orally supplemented with Panax ginseng roots, Shilajit, Withania somnifera root, Tribulus terrestris Fruits, Turnera diffusa leaves, Ptychopetalum olacoides bark and Pausinystalia yohimbe bark. Our goal was to study the changes in the sperm motion traits of fresh and post-thaw semen of subfertile buffalo bull during the period of dietary supplementation herbs and as well as pre and post supplementation.

\section{Materials and Methods}

\section{Ethical approval}

The experiment was carried out after the approval by the Institutional Animal Ethics Committee with reference number GADVASU/2016/IAEC/35/02 dated 17.07. 2016.

\section{Procurement of herb and chemicals}

Herbs were procured from the Indian Drugs and Botanical Herbs Company, New Delhi, India. The chemical reagents were procured from Sisco Research Laboratories Pvt. Ltd. [SRL), India.

\section{Experimental animals}

The present study was conducted on 3 subfertile buffalo bulls (aged around 5 years and 700-750 kilograms of body weight each) were having a history of poor semen quality (pre-freeze individual motility $<60 \%$, postthaw individual motility $<40 \%$ ).

Buffalo bulls were being maintained loosely in half walled concrete sheds in individual pens (covered area - $12 \times 10 \mathrm{ft}$ and uncovered area $25 \times 10 \mathrm{ft}$ ) at bull station, Guru Angad Dev Veterinary and Animal Sciences University (GADVASU), Ludhiana, India (Latitude/ Longitude, $30.55^{\circ} \mathrm{N}, 75.54^{\circ} \mathrm{E}$ ). All the animals were being fed according to standard feeding schedule along with ad libitum green fodder. The bulls were being given an exercise for half an hour on alternate days.

\section{Experimental design and semen collection}

The trial was comprised of three phases viz. pre-treatment, treatment and post-treatment phase of 60 days each. During the treatment phase, buffalo bulls were orally supplemented with herbal mixture daily (Panax ginseng 
roots, Shilajit, Withania somnifera roots, Tribulus terrestris fruits, Turnera diffusa leaves, Ptychopetalum olacoides bark each of $400 \mathrm{mg} / 100 \mathrm{~kg}$ body weight and Pausinystalia yohimbe bark @ 300 mg/100 kg body weight of bulls). All the animals were examined for physiological parameters (mucous membrane, body temperature, respiration rate and pulse rate) and adverse clinical signs (salivation, lacrimation and sweating) during the experiment. Semen was collected twice a week during pre-treatment, treatment and post-treatment phases. A total of 144 semen ejaculates (16 ejaculates/bull/ phase) were subjected for the study.

\section{Assessment of sperm motion traits}

Sperm motion traits were studied according to Kumar et al., (2004) by using Computer Assisted Sperm Analysis software (Biovis CASA 2000, version 4.59, Expert Vision Labs Pvt. Limited, India) with the set up as shown in table 2. The sperm concentration of the sample was adjusted to 20 million sperms $/ \mathrm{ml}$ using Tris egg yolk extender and Tris buffer for pre-freez and post-thaw semen, respectively. A drop $(5 \mu \mathrm{l})$ of diluted semen was placed in a pre-warmed Biovis Shukratara chamber (Expert Vision Labs Pvt. Limited, India). The motion traits were recorded under 10x of phase contrast microscope (Nikon Eclipse E600, Tokyo, Japan) attached with the warm stage.

\section{Statistical Analyses}

All data are presented as the mean \pm standard error. Normality of data was checked by Shapiro-Wilk Test. Homogeneity of variance was analyzed by Levene's test. Data were analyzed by one way ANOVA followed by Tukey's HSD post hoc test for the comparison of treatment phases (IBM SPSS Statistics version 22). Statistical significance was considered at $\mathrm{P}<0.05$.

\section{Results and Discussion}

\section{Sperm motion traits}

In present study, sperm motion traits of subfertile buffalo bull semen were assessed by Computer Assisted Sperm Analysis software (Table 1).

\section{Pre-freeze semen}

The sperm motion traits of pre-freeze semen such as, individual motility $(57.72 \pm 5.53$ vs. $73.55 \pm 2.89)$, rapid progressive motility $(25.17 \pm 5.48$ vs. $34.36 \pm 3.00)$ and VCL $(71.85 \pm 5.20$ vs. $90.85 \pm 2.2)$ were significantly $(\mathrm{P}<0.05)$ higher during treatment phase as compared to pre-treatment phase, respectively. However, ALH (6.18 \pm 0.54 vs. $4.57 \pm 0.36)$ and DNC (390.77 \pm 69.13 vs. $251.53 \pm 20.67)$ were significantly $(\mathrm{P}<0.05)$ reduced during treatment phase as compared to pre-treatment phase, respectively. Further, VCL $(86.11 \pm 19.16$ vs. $71.85 \pm 5.20)$, VSL $(43.39 \pm 4.55$ vs. $51.78 \pm 3.81)$, STR $(84.63 \pm$ 1.92 vs. $92.49 \pm 0.49)$ and $\mathrm{BCF}(10.35 \pm 0.54$ vs. $19.28 \pm 0.93)$ were significantly $(\mathrm{P}<0.05)$ increased during post-treatment phase in contrast to pre-treatment phase, respectively. Moreover, ALH (6.18 \pm 0.54 vs. $3.26 \pm 0.26)$, DNC (390.77 \pm 69.13 vs. $231.38 \pm 12.50)$ and DNM (10.85 \pm 0.80 vs. $6.54 \pm 1.09)$ were significantly $(\mathrm{P}<0.05)$ reduced during posttreatment phase as compared to pre-treatment phase. The remaining sperm motion traits such as slow progressive motility, VAP, LIN and WOB were similar $(\mathrm{P}>0.05)$ in all the three phases.

\section{Post-thaw semen}

Herbal treatment significantly $(\mathrm{P}<0.05)$ improved the post-thaw individual motility during the treatment phase $(41.72 \pm 0.33 \%)$ and post-treatment phase $(40.36 \pm 2.40 \%)$ in contrast to pre-treatment phase (32.85 \pm $2.40 \%)$. 
Table.1 Effects of herbal treatment on pre-freeze and post-thaw sperm motion traits (Mean \pm SE) of subfertile buffalo bulls during different phases

\begin{tabular}{|c|c|c|c|c|c|c|}
\hline \multirow{2}{*}{ Sperm motion traits } & \multicolumn{3}{|c|}{ Pre-freeze semen } & \multicolumn{3}{|c|}{ Post thaw semen } \\
\hline & Pre-treatment & Treatment & Post-treatment & Pre-treatment & Treatment & Post-treatment \\
\hline Motile (\%) & $57.72 \pm 5.53^{\mathrm{a}}$ & $73.55 \pm 2.89^{b}$ & $62.01 \pm 3.05^{\mathrm{a}}$ & $32.85 \pm 2.40^{\mathrm{a}}$ & $41.72 \pm 0.33^{b}$ & $40.36 \pm 2.40^{b}$ \\
\hline Rapid Prog (\%) & $25.17 \pm 5.48^{\mathrm{a}}$ & $34.36 \pm 3.00^{b}$ & $31.91 \pm 3.67^{\mathrm{a}, \mathrm{b}}$ & $12.30 \pm 1.79^{\mathrm{a}}$ & $16.92 \pm 0.62^{b}$ & $15.63 \pm 0.70^{\mathrm{a}, \mathrm{b}}$ \\
\hline Slow Prog (\%) & $22.82 \pm 2.73^{\mathrm{a}}$ & $31.47 \pm 3.53^{\mathrm{a}}$ & $26.05 \pm 2.70^{\mathrm{a}}$ & $16.64 \pm 2.27$ & $11.45 \pm 1.00$ & $20.49 \pm 3.35$ \\
\hline VCL (um/sec) & $71.85 \pm 5.20^{\mathrm{a}}$ & $90.85 \pm 2.21^{b}$ & $86.11 \pm 19.16^{\mathrm{b}}$ & $73.82 \pm 3.03$ & $72.37 \pm 2.37$ & $72.99 \pm 2.43$ \\
\hline VAP (um/sec) & $47.76 \pm 4.37^{\mathrm{a}}$ & $52.53 \pm 3.64^{\mathrm{a}}$ & $54.58 \pm 20.57^{\mathrm{a}}$ & $43.16 \pm 1.46$ & $41.59 \pm 1.07$ & $41.73 \pm 1.11$ \\
\hline VSL (um/sec) & $43.39 \pm 4.55^{\mathrm{a}}$ & $47.44 \pm 3.61^{\mathrm{a}, \mathrm{b}}$ & $51.78 \pm 3.81^{\mathrm{b}}$ & $38.51 \pm 1.69$ & $36.78 \pm 1.31$ & $35.90 \pm 1.78$ \\
\hline LIN (\%) & $59.60 \pm 3.71^{\mathrm{a}, \mathrm{b}}$ & $65.72 \pm 2.16^{\mathrm{b}}$ & $59.08 \pm 1.50^{\mathrm{a}}$ & $47.36 \pm 1.28$ & $46.23 \pm 1.73$ & $49.73 \pm 2.48$ \\
\hline STR (\%) & $84.63 \pm 1.92^{a}$ & $87.72 \pm 1.57^{\mathrm{a}}$ & $92.49 \pm 0.49^{b}$ & $81.78 \pm 2.02$ & $82.73 \pm 2.06$ & $82.62 \pm 2.05$ \\
\hline WOB \%() & $68.28 \pm 3.74^{\mathrm{a}, \mathrm{b}}$ & $73.22 \pm 2.07^{\mathrm{a}}$ & $62.58 \pm 1.42^{b}$ & $54.34 \pm 0.80$ & $52.65 \pm 1.22$ & $53.15 \pm 2.23$ \\
\hline BCF (hz) & $10.35 \pm 0.54^{\mathrm{a}}$ & $14.40 \pm 1.28^{\mathrm{a}}$ & $19.28 \pm 0.93^{b}$ & $16.17 \pm 0.65$ & $15.64 \pm 0.45$ & $14.90 \pm 10.82$ \\
\hline ALH (um) & $6.18 \pm 0.54^{\mathrm{a}}$ & $4.57 \pm 0.36^{b}$ & $3.26 \pm 0.26^{\mathrm{c}}$ & $2.72 \pm 0.07$ & $2.64 \pm 0.11$ & $7.19 \pm 4.56$ \\
\hline DNC (squm/sec) & $390.77 \pm 69.13^{a}$ & $251.53 \pm 20.67^{b}$ & $231.38 \pm 12.50^{b}$ & $178.21 \pm 12.11$ & $179.46 \pm 8.72$ & $161.65 \pm 11.47$ \\
\hline DNM (squm/sec) & $10.85 \pm 0.80^{\mathrm{a}}$ & $7.35 \pm 0.76^{\mathrm{a}, \mathrm{b}}$ & $6.54 \pm 1.09^{b}$ & $6.85 \pm 0.39$ & $6.50 \pm 0.48$ & $7.36 \pm 0.49$ \\
\hline
\end{tabular}

Values with different superscripts $\left({ }^{\mathrm{a}, \mathrm{b}, \mathrm{c}}\right)$ within a row differ significantly (Tukey's HSD, $\mathrm{P}<0.05$ ). 
Table.2 Analysis set-up for CASA (Biovis CASA 2000, version 4.59)

\begin{tabular}{|c|c|}
\hline \multicolumn{2}{|c|}{ Optic calibration } \\
\hline Parameters & Settings \\
\hline Magnification & $\begin{array}{l}\text { Objective } 10 \mathrm{X} \text { Phase } \\
\text { Image Pixels - } 1.48 \text { pixels/unit }\end{array}$ \\
\hline Camera frequency (FPS) & 160 \\
\hline Frame rate (FPS) & 60 \\
\hline Frames acquired (FPS) & 60 \\
\hline \multicolumn{2}{|l|}{ Detection of motility parameters } \\
\hline Non progressive limit $(\mu \mathrm{m} / \mathrm{sec})$ & $0-10$ \\
\hline Slow progressive limit - $(\mu \mathrm{m} / \mathrm{sec})$ & $10-25$ \\
\hline Rapid progressive limit - $(\mu \mathrm{m} / \mathrm{sec})$ & $>=25$ \\
\hline \multicolumn{2}{|l|}{ Detection of velocity parameters } \\
\hline Maximum velocity for tracking $(\mu \mathrm{m} / \mathrm{sec})$ & 150 \\
\hline Minimum VCL $(\mu \mathrm{m} / \mathrm{sec})$ & $>25$ \\
\hline Minimum VAP $(\mu \mathrm{m} / \mathrm{sec})$ & $>10$ \\
\hline Minimum VSL $(\mu \mathrm{m} / \mathrm{sec})$ & $>1$ \\
\hline Minimum track Length (\% of frames) & 51 \\
\hline \multicolumn{2}{|l|}{ Shape and size } \\
\hline Area $(\mu \mathrm{m})$ & $1-9999$ \\
\hline Axis major $(\mu \mathrm{m})$ & $5-16$ \\
\hline Axis minor $(\mu \mathrm{m})$ & $3-10$ \\
\hline \multicolumn{2}{|l|}{ Stage configuration - BiovisShukratara } \\
\hline Chamber depth (micron) & 10 \\
\hline Chamber area $\left(\mathrm{mm}^{2}\right)$ & $100 \times 0.01$ \\
\hline Volume (vL) & 5 \\
\hline
\end{tabular}

Further, rapid progressive motility was significantly higher during the treatment phase $(16.92 \pm 0.62 \%)$ as compared to pretreatment phase $(12.30 \pm 1.79 \%)$. However, other post-thaw sperm motion traits such as slow progressive motility, VCL, VAP, VSL, LIN, STR, WOB, BCF, ALH, DNC and DNM were similar $(\mathrm{P}>0.05)$ across the three phases.

Improvement of sperm motion traits may be due the complex interactions or synergetic or adaptogenic or antioxidant effects of bioactive components like Ginsenosides of Panax ginseng (Leung et al., 2013), humic acid, fulvic acid and Dibenzo Alpha Pyrones of Shilajit (Sharma et al., 2003; Ghosal, 1990), sitoindosides VII-X and with a ferin A of Withania somnifera (Bhattacharya et al., 1997), protodioscin of Tribulus terrestris (Gauthaman et al., 2002), Apigenin of Turnera diffusa (Kumar et al., 2006), Ptychopetalum olacoides (Antunes et al., 2001) and yohimbine of Pausinystalia yohimbe (Neha et al., 2017).

Improvement of sperm motion traits without any adverse effects following herbal treatment might be due to Panax ginseng, which enhances the level of cAMP-responsive element modulator messenger (Hwang et al., 2010; Park et al., 2007) and ginsenoside Rg1 (Dae and You 2013). Similar results have also been reported in fresh semen of bulls, men, 
mice, rats and cocks following individual supplementation of Shilajit, Withania somnifera and Tribulus terrestris (Salgado et al., 2017; Khaleghi et al., 2016; Eskandari et al., 2016; Sharaway et al., 2015; Mostafa and El-Khalik 2014; Ambiye et al., 2013; Mishra et al., 2012; Adaay et al., 2012; Biswas et al., 2010; Ahmad et al., 2009; Grigorovaet al., 2008; Hadi, 1970).Contrary to our data in vitro addition of Panax ginseng extract to boar semen has shown no significant effects on sperm motion traits (Gray et al., 2016).

However, no scientific extensive data are available in bulls for the comparison of our results. So, further, studies are needed for the detailed understanding of the effects of the herbs on semen quality of subfertile buffalo bulls.

Present study clearly indicated that, the dietary supplementation of herbal mixture containing Panax ginseng roots, Shilajit, Withania somnifera roots, Tribulus terrestris fruits, Turnera diffusa leaves; Ptychopetalum olacoides bark each @ 400 mg/100 kg body weight and Pausinystalia yohimbe bark @ $300 \mathrm{mg} / 100 \mathrm{~kg}$ body weight of bulls for 60 days improved the sperm motion traits of prefreeze and post-thaw semen samples in subfertile buffalo bulls.

\section{Acknowledgements}

The authors are thankful to the Director of Livestock Farms, GADVASU, Ludhiana, Punjab (India) for providing animals for the experiment.

\section{References}

Adaay, M.H. and Mattar, A.G., 2012. Effect of aqueous and ethanolic extracts of Tribulus terrestris, Phoenix dactylifera and Nasturtium officinale mixture on some reproductive parameters in male mice. Bag. Sci. J., 9: 640-50.
Ahmad, M.K., Mahdi, A.A. and Shukla, K.K., 2009. Withania somnifera improves semen quality by regulating reproductive hormone levels and oxidative stress in seminal plasma of infertile male. FertilSteril., 94: 989-96.

Ambiye, V.R., Langade, D., Dongre, S., Aptikar, P., Kulkarni, M. and Dongre, A., 2013. Clinical evaluation of the spermatogenic activity of the root extract of Ashwagandha (Withania somnifera) in oligospermic males: a pilot study. $J$ Evid Based Complementary Altern Med., 2013: 1-6.

Andrabi, S.M.H., 2009. Factors Affecting the Quality of Cryopreserved Buffalo (Bubalus bubalis) Bull Spermatozoa. Reprod Dom Anim., 44: 552-569.

Antunes, E., Gordo, W.M., de Oliveira, J.F., Teixeira, C.E., Hyslop, S. and Nucci, D.G. (2001).The relaxation of isolated rabbit Corpus Cavernosum by the Herbal Medicine Catuama ${ }^{\circledR}$ and its Constituents. Phytother Res., 15: 416-421.

Bansal, A.K. and Bilaspuri, G.S., 2011.Impacts of oxidative stress and antioxidants on semen functions. Vet Med Int., 2011: 1-7.

Benedetti, S., Tagliamonte, M.C., Catalani, S., Primiterra, M., Canestrari, F., Stefani, S.D., Palini, S. and Bulletti, C., 2012. Differences in blood and semen oxidative status in fertile and infertile men and their relationship with sperm quality. Reprod Biomed Online., 25: 300-6.

Bhattacharya, S.K., Satyan, K.S. and Ghosal, S., 1997. Antioxidant activity of glycol with anolides from Withania somnifera. Indian J Exp Biol., 35: 236-239.

Biswas, T.K., Pandit, S., Mondal, S., Biswas, S.K., Jana, U., Ghosh, T., Tripathi, P.C., Debnath, P.K., Auddy, R.G. and Auddy, B., 2010. Clinical evaluation of spermatogenic activity of processed shilajit in oligospermia. Andrologia, 42: 48-56.

Chatterjee, S. and Gagnon, C., 2001.Production of reactive oxygen species by spermatozoa undergoing cooling, freezing 
and thawing. Mol. Reprod. Dev., 59: 45158.

Cheema, R.S., Bansal, A.K. and Bilaspuri, G.S., 2009. Manganese provides antioxidant protection for sperm cryopreservation that may offer new consideration for clinical fertility. Oxid Med Cell Longev., 2: 152-9.

Dae, Y.K. and You, J.H., 2013. Effects of ginsenoside-Rg1 on post-thawed miniature pig sperm motility, mitochondria activity and membrane integrity. J. Embryo Transf., 28: 63-71.

Eskandari, M., Jani, S., Kazemi, M., Zeighami, H., Yazdinezhad, A., Mazloomi, S. and Shokri, S., 2016.Ameliorating Effect of Ginseng on Epididymo-Orchitis Inducing Alterations in Sperm Quality and Spermatogenic Cells Apoptosis following Infection by Uropathogenic Escherichia coli in Rats. Cell Journal, 18: 446-57.

Fujii, J., Iuchi, Y., Matsuki, S. and Ishii, T., 2003. Cooperative function of antioxidant and redox systems against oxidative stress in male reproductive tissues. Asian $J$ Androl., 5: 231-42.

Gauthaman, K., Adaikan, P.G. and Prasad, R.N., 2002.Aphrodisiac properties of Tr.Terrestris extract (Protodioscin) in normal and castrerted rats.Life Sci., 71: 1385-1396.

Ghosal, S., 1990.Chemistry of Shilajit, an immunomodulatory Ayurvedic rasayan. Pure Appl. Chem., 62: 1285-1288.

Gray, S.L., Lackey, B.R. and Boone, W.R., 2016. Effects of Panax ginseng, zearalenol and estradiol on sperm function. J Ginseng Res., 40: 251-59.

Greco, E., Iacobelli, M., Rienzi, L., Ubaldi, F., Ferrero, S. and Tesarik, J., 2005.Reduction of the incidence of sperm DNA fragmentation by oral antioxidant treatment. J. Androl., 26: 349-53.

Grigorova S, Kashamov B, Sredkova V, Surdjiiska S and Zlatev H., 2008. Effect of Tribulus terrestris extract on semen quality and serum total cholesterol content in white plymouth rock-mini cocks. Biotechnology in Animal Husbandry, 24: 139-46.
Hadi, M.A., 1970. Clinical Trial with Tentexforte in Functional impotency of breeding bulls. Probe (IX)., 4: 173-75.

Hwang, S.Y., Sohn, S.H., Wee, J.J., Yang, J.B., Kyung, J.S., Kwak, Y.S., Kim, S.W. and Kim, S.K., 2010. Panax ginseng Improves Senile Testicular Function in Rats. $J$ Ginseng Res., 34: 327-35.

Kadirvel, G., Kumar, S. and Kumaresan, A., 2009.Lipid peroxidation, mitochondrial membrane potential and DNA integrity of spermatozoa in relation to intracellular reactive oxygen species in liquid and frozen-thawed buffalo semen. Anim Reprod. Sci., 114: 125-34.

Khaleghi, S., Bakhtiari, M., Asadmobini, A. and Esmaeili, F., 2016.Tribulus terrestris Extract Improves Human Sperm Parameters in vitro. J Evid Based Complementary Altern Med., 22: 407-12.

Khatun, M., Kaur, S., Kanchan, and Mukhopadhyay, C. S., 2013.Subfertility Problems Leading to Disposal of Breeding Bulls. Asian-Australas. J Anim Sci, 26: 303-308.

Koonjaenak, S., Pongpeng, P., Wirojwuthikul, S., Johannisson, A., Kunavongkrit, A. and Rodriguez-Martinez, H., 2007. Seasonality affects post-thaw plasma membrane intactness and sperm velocities in spermatozoa from Thai AI swamp buffaloes (Bubalus bubalis). Theriogenology, 67:1424-1435.

Krumova, K. and Cosa, G., 2016. Overview of Reactive Oxygen Species, in Singlet Oxygen. J. Nanosci. Nanotechnol., 1: 1-2.

Kumar, S. and Sharma, A., 2006.Apigenin: The Anxiolytic Constituent of Turneraaphrodisiaca. Pharm. Biol.. 44: 84-90.

Leung, K.W. and Wong, A.S.T., 2013. Ginseng and male reproductive function. Spermatogenesis. 3: 1-6.

Mishra, R.K., Verma, H.P., Singh, N. and Singh, S.K., 2012. Male Infertility: Lifestyle and Oriental Remedies. J. Sci. Res. Adv., 56: 93-101.

Mostafa, A.S. and El-Khalik, A.H., 2014. Assessment of protective and antioxidant 
properties of Tribulus terrestris fruits against testicular toxicity in rats. $J$ Intercult Ethnopharmacol., 3: 113-18.

Neha, Ansari MM and Khan HA., 2017.Yohimbine hydrochloride ameliorates collagen type-II-induced arthritis targeting oxidative stress and inflammatory cytokines in Wistar rats. Environ Toxicol., 32: 619-629.

Oral, O., Kutlu, T., Aksoy, E., Ficicioglu, C., Uslu, H. and Turul, S., 2006. The effects of oxidative stress on outcomes of assisted reproductive techniques. $J$ Assist Reprod Genet., 23: 81-5.

Parisi, A.M., Thompson S.K., Kaya, A., Memili, E., 2014.Molecular, cellular, and physiological determinants of bull fertility. Turk J Vet Anim Sci, 38: 637642.

Park, W.S., Shin, D.Y., Kim, R., Yang, W.M., Chang, M.S. and Park, S.K., 2007. Panax ginseng induces spermatogenesis in rats through the activation of CAMP responsive element modulator (CREM). American Society for Reproductive Medicine, 88: 1000-2.

Rhee, S.G., 2006. H2O2, a necessary evil for cell signaling.Science, 312: 1882-3.

Salgado, R.M., Marques-Silva, M.H., Gonçalves, E., Mathias, A.C., Aguiar, J.G. and Wolff, P., 2017.Effect of oral administration of Tribulus terrestris extract on semen quality and body fat index of infertile men. Andrologia, 49: 16.

Shamsi, M.B., Venkatesh, S., Kumar, R., Gupta, N.P., Malhotra, N., Singh, N.,
Mittal, S., Arora, S., Arya, D.S., Talwar, P., Sharma, R.K. and Dada, R., 2010. Antioxidant Levels in Blood and Seminal Plasma and Their Impact on Sperm Parameters in Infertile Men. Indian $J$ Biochem. Biophys., 47: 38-43.

Sharaway, S.M., Saleh, N.H., Attalah, S.A., Absy, G.M. and Doaa, H.K., 2015.Effect of plant extract of Tribulus terrestris and probiotics on the reproductive performance, total cholesterol and testosterone hormone levels of rams. MENASJ., 1: 14-9.

Sharma, M., Yaqoob, B., Singh, A., Sharma, N. and Rawat S., 2017. Effect of Temperature Humidity Index on Semen Quality of Bovine Bull. Int.J.Curr. Microbiol.App.Sci., 6: 1822-1830.

Sharma, P., Jha, J., Shrinivas, V., Dwivedi, L.K., Suresh, P. and Sinha, M., 2003.Shilajit: evaluation of its effects on blood chemistry of normal human subjects. Anc. Sci. Life., 23: 114-119.

Tunc, O., Thompson, J. and Tremellen, K., 2009. Improvement in sperm DNA quality using an oral antioxidant therapy. Reproductive Bio Medicine Online., 18: 761-68.

Vaisberg, C.N., Jelezarsky, L.V., Dishlianova, B. and Chaushev, T.A., 2005. Activity, substrate detection and immunolocalization of glutathione peroxidase (GPx) in bovine reproductive organs and semen. Theriogenology., 64: 416-28.

\section{How to cite this article:}

Shivkumar, Ajeet Kumar, M. Honparkhe, A.K. Singh and Brar, P.S. 2018. Effects of Dietary Herbal Supplementation on CASA Based Sperm Motion Traits in Subfertile Buffalo Bulls (Bubalus bubalis). Int.J.Curr.Microbiol.App.Sci. 7(03): 2543-2550.

doi: https://doi.org/10.20546/ijcmas.2018.703.294 